\title{
An evaluation of the effect of partial hippocampal kindling on place navigation by rats in the Morris water task
}

\author{
ROBERT J. SUTHERLAND \\ University of New Mexico, Albuquerque, New Mexico \\ L. S. LEUNG \\ University of Western Ontario, London, Ontario, Canada \\ and \\ MICHAEL P. WEISEND, JENNIFER SCHLIFE, and ROBERT J. MCDONALD \\ University of New Mexico, Albuquerque, New Mexico
}

\begin{abstract}
We report the results of two experiments that examine the effects of partial kindling on acquisition and retention of place navigation in the Morris water task. Rats were implanted bilaterally in subfield CA1 of the hippocampus with electrodes for electrical stimulation and EEG recording. Half of the rats in each experiment received 20 afterdischarges (ADs) on 4 consecutive days; the other half received low-frequency stimulation that did not induce ADs. The rats in the first experiment were trained beginning the day after the last $\mathrm{AD}$ to navigate to a platform hidden in a fixed location in the pool. No differences in performance were detected between groups. The rats in the second experiment had received extensive training before ADs with a hidden platform that changed its location within the pool between days. Beginning either 1 day, 1 week, or 1 month after the last $\mathrm{AD}$, these rats were tested in the moving-platform task both in a new room and in the original training room. The rats receiving ADs performed significantly worse in both rooms than did control rats 1 day and 1 week, but not 1 month, after the last AD. These results extend the generality of earlier findings of impaired radial-arm maze performance after partial hippocampal kindling in rats and support the idea that some consequence of hippocampal ADs disrupts normal functioning of these networks in spatial learning.
\end{abstract}

Epileptiform activity in hippocampal circuitry has been shown to affect behavior in a variety of situations. One method has involved the electrical induction of an afterdischarge (AD) in the hippocampal formation. A single hippocampal $\mathrm{AD}$ has been shown to be able to disrupt recall of information acquired before the AD. This disruption has been demonstrated using retention of passive avoidance learning (Kesner \& Doty, 1968; McDonough $\&$ Kesner, 1971), retention of which arms were visited in an eight-arm radial maze (Knowlton, Shapiro, \& Olton, 1989; Olton \& Wolf, 1981), and retention of item recall in patients (Halgren \& Wilson, 1985). A simple account of these data is that the $\mathrm{AD}$ produces retrograde amnesia for recently acquired information. It does not appear that in these situations the hippocampal AD produces anterograde effects. A related question is whether repeated production of hippocampal ADs can bring about significant

This research was supported by NIH R01-NS25383. The authors wish to thank B. Kim and N. Castillo for their technical assistance. Correspondence should be addressed to R. J. Sutherland, Department of Psychology, Logan Hall, University of New Mexico, Albuquerque, NM 87131-1161 (e-mail: sutherla@unm.edu).

-Accepted by previous editor, Paul E. Gold functional deficits. Lopes da Silva, Gorter, and Wadman (1986) showed that repeated hippocampal ADs to the point of behavioral convulsions produced a deficit in eightarm radial maze performance that lasted $24 \mathrm{~h}$. They did not test their animals beyond $24 \mathrm{~h}$. Leung and co-workers have tested for longer lasting deficits in the radial arm maze after repeated hippocampal ADs involving induction of full seizures (Leung, Boon, Kaibara, \& Innis, 1990) or only partial kindling (Leung \& Shen, 1991). Both of these procedures can produce deficits in radial arm maze performance that last at least 3 weeks.

In the present report, we examine possible effects of repeated hippocampal ADs (partial kindling) on performance in the Morris water task. This task is especially well suited to extending our understanding of the behavioral deficit produced by partial hippocampal kindling for at least two reasons. First, prior work has shown that acquisition of place information in this task is sensitive to various types of hippocampal disruption. These include nonspecific lesions such as hippocampal aspiration, electrolytic damage, and transections of fornix or perforant pathway (Morris, Garrud, Rawlins, \& O'Keefe, 1982; Sutherland, Kolb, \& Whishaw, 1982; Sutherland \& Rodriguez, 1989; Sutherland, Whishaw, \& Kolb, 1983), as well as very selective subtotal lesions involving each of 
the major hippocampal subfields (CA1, CA3) and components of the dentate gyrus (Auer, Jensen, \& Whishaw, 1989; Sutherland, Hoesing, \& Whishaw, 1990; Sutherland et al., 1983; Whishaw, 1987). Furthermore, certain manipulations of hippocampal synaptic plasticity (Castro, Silbert, McNaughton, \& Barnes, 1989; Morris, Anderson, Lynch, \& Baudry, 1986) have been shown to disrupt acquisition of Morris water task performance (but see Sutherland, Dringenberg, \& Hoesing, 1993).

Second, unlike the radial arm maze, the Morris water task does not have an explicit working memory (Morris, 1983) requirement. On some views (e.g., Olton, Becker, \& Handelmann, 1979), such a requirement may make a behavioral task especially sensitive to alterations in hippocampal circuitry. Use of the Morris water task will therefore permit an evaluation of the necessity of a working memory component in yielding an impairment after partial hippocampal kindling. In contrast to this difference between tasks, in their "standard versions" these tasks require the subject to use the spatial layout of cues around the experimental context to accurately navigate to goal locations. On many views (e.g., O'Keefe \& Nadel, 1978; Sutherland \& Rudy, 1989), this requirement of a task confers a special sensitivity to alterations in hippocampal circuitry. Thus, because of the clear sensitivity of the Morris water task to various types of disruption of hippocampal function and its partial overlap in behavioral requirements with the radial arm maze, we sought to use it to extend our understanding of the functional impairments brought about by the alterations in hippocampal circuitry following repeated ADs.

Kindled rats were reported to be not different from control rats in the acquisition or retention of the Morris water task using a stationary hidden platform (Cain, Hargreaves, Boon, \& Dennison, 1993; McNamara, Kirkby, dePape, Skelton, \& Corcoran, 1993). In the present experiments, we address this issue further using two versions of the Morris water task. We tested the effects of partial hippocampal kindling in rats that were naive to the task. These rats acquired the "standard" version, involving a single, fixed, hidden platform location (Morris, 1981). In a second experiment, we took advantage of a procedure developed by Whishaw $(1985,1987)$ in which the hidden platform location is changed each day but remains the same for all trials on a given day. After training in this task, normal rats show essentially one trial place learning each day they are tested. Whishaw and co-workers have shown that his procedure is exquisitely sensitive, even to partial damage in the hippocampal CA1 subfield caused by experimental ischemia (Auer et al., 1989). Our rats were trained in this version before ADs, which allowed us to measure the accuracy of place learning at specific times after a series of ADs.

\section{METHOD}

\section{Subjects}

Thirty male Long-Evans hooded rats were used. Twelve rats served in Experiment 1 and 18 rats in Experiment 2. They were housed individually in the Department of Psychology vivarium at the University of New Mexico and were maintained on a 12:12-h light:dark cycle. Water and a standard laboratory rodent diet were continually available. At the time of surgery, the rats weighed between 325 and $425 \mathrm{~g}$.

\section{Apparatus}

Two circular white swimming pools $(1.4 \mathrm{~m}$ in diameter, $0.8 \mathrm{~m}$ in height) were used. They were filled with water $\left(20^{\circ} \mathrm{C}\right)$ rendered opaque by dissolving approximately $1,500 \mathrm{ml}$ of instant skim milk powder. The pools were located in two rooms that differed in size, shape, and furnishings. A clear Plexiglas platform was positioned in the pool with its surface $1.5 \mathrm{~cm}$ below the water surface. Behavior during each trial was recorded using an automated, computerbased, video tracking system (HVS Image Analysis, VP112). The measures included time to find the platform, swim path length, proportion of swim distance in each quadrant, proportion of swim distance in an annulus adjacent to the pool wall, and the initial heading error over the first $25 \mathrm{~cm}$ of a swim. Electrophysiological procedures were conducted using a BrainWave system running on a 486-based microcomputer. Amplification was provided by a preamplifier (Grass P15D) and amplifier (Neurolog) circuit. Electrical stimulation was provided by a programmable pulse former (AMPI Master-8) and optically isolated constant current stimulator (Isoflex).

\section{Surgery and Recording}

Rats were anesthetized with sodium pentabarbital $(65 \mathrm{mg} / \mathrm{kg}$, i.p.). Teflon-coated stainless steel electrodes were implanted into the $\mathrm{CA} 1$ region of the left and right hippocampus using aseptic techniques. The coordinates, with the skull leveled between bregma and lambda, were $3.2 \mathrm{~mm}$ posterior to bregma, $3.0 \mathrm{~mm}$ lateral, and $2.2 \mathrm{~mm}$ below the dura. Spontaneous extracellular unit and field potentials were monitored using a Grass audio monitor during lowering of each electrode to aid in accurate positioning in CAl stratum radiatum. Stainless steel jewelers' screws were tapped into the skull to provide for ground connections for the recording and stimulation circuits. The entire electrode assembly was secured to the skull with additional jewelers' screws and dental acrylic. At the completion of surgery, the rats received injections of penicillin (600 IU i.m.), and as they recovered from anesthesia they received injections of morphine sulfate $(5 \mathrm{mg} / \mathrm{kg}$, s.c.) for postoperative analgesia. At least 7 days were permitted for recovery before beginning behavioral training and electrophysiology.

\section{Afterdischarge Induction}

Afterdischarges were produced by stimulating the rats using 400 $\mu \mathrm{A}, 100-\mathrm{Hz}, 0.1-\mathrm{msec}$ rectangular monophasic pulses for $1 \mathrm{sec}$. These parameters reliably produced ADs in every rat. The behavior of the rats was monitored continuously during sessions. With these stimulation parameters, we had previously found that there was no progression in behavioral manifestations of seizure activity beyond clear stimulation-induced alert immobility. EEG from the contralateral CA 1 electrode was continuously recorded, digitized, and stored on a rewritable optical disk before, during, and for up to 3 min after ADs. The EEG signal was filtered ( $1 / 2$ amplitude low frequency, $1 \mathrm{~Hz} ; 1 / 2$ amplitude high frequency, $10 \mathrm{kHz}$ ), and the total amplification was $200 \times$. Signals were displayed on a Nicolet digital storage scope and continuously monitored on a Grass audio monitor. On 4 consecutive days, the experimental rats received one $\mathrm{AD}$ each hour for 5 consecutive hours. Control rats received the same number of identical stimulus pulses, but at $0.1 \mathrm{~Hz}$.

\section{Behavioral Procedure: Experiment 1}

Half of the rats received ADs and half were low-frequency stimulation control rats who were treated identically except that no ADs were induced. Twenty-four hours after the last AD, all rats were trained in the Morris water task. They received eight trials 
each day for 5 days. The rats were released once from each of the cardinal compass directions at the pool's perimeter in each block of four trials. The maximum trial duration was $90 \mathrm{sec}$. The hidden platform was positioned in the center of the northwest quadrant of the pool. At the end of the 2nd day of training and again at the end of training, all rats received one trial with the platform removed from the pool to test for searching preference. On the probe trials, proportion of swim path length in the four quadrants was analyzed.

\section{Behavioral Procedure: Experiment 2}

All rats were trained for 14 days in the moving hidden platform version of the Morris water task before the 20 ADs were induced. The rats had not received training prior to electrode implantation. The rats received eight trials each day, as described above. Each day the platform was moved to a new position according to a pseudorandom sequence, but for all the trials in a given day, the platform remained in the same position. The platform was never positioned in the exact center of the pool, nor was it positioned closer than $5 \mathrm{~cm}$ to the pool wall. Further, the center of the platform was never positioned within $5 \mathrm{~cm}$ of a previously selected position. Half of the rats received $\mathrm{ADs}$ and half served as controls, as described above. ADs were induced starting approximately $2 \mathrm{~h}$ after the last training session. One day, 1 week, and 1 month after the last $A D$, the rats were tested in the moving-platform task again. During these tests, all rats received four trials in the original training room, followed by four trials in a pool in a new room. A new, hidden platform location was selected at each time point and all rats were exposed to the same sequence. The sequence was around $8 \mathrm{~cm}$ from the centers of the northwest, northeast, and southwest quadrants to ensure large differences among goal sites and to avoid "easy" locations very near release points.

\section{RESULTS}

\section{Experiment 1}

Consistent with a report by Leung, Zhao, and Shen (1994), the average duration of the last induced AD was

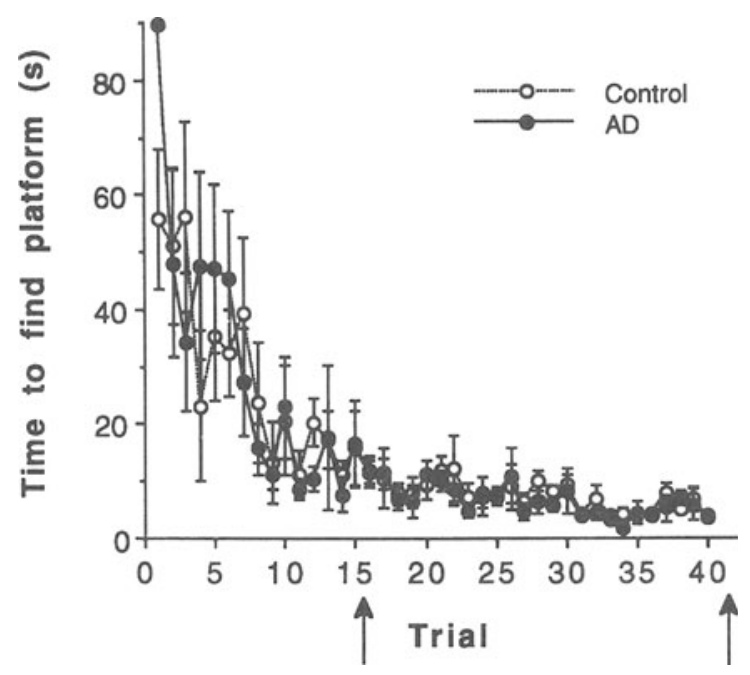

Figure 1. Average time to find the hidden platform on each trial in the fixed-location version of the Morris water task for rats after induction of 20 afterdischarges (ADs) or control stimulation. The arrows indicate when the no-platform probe trials took place.

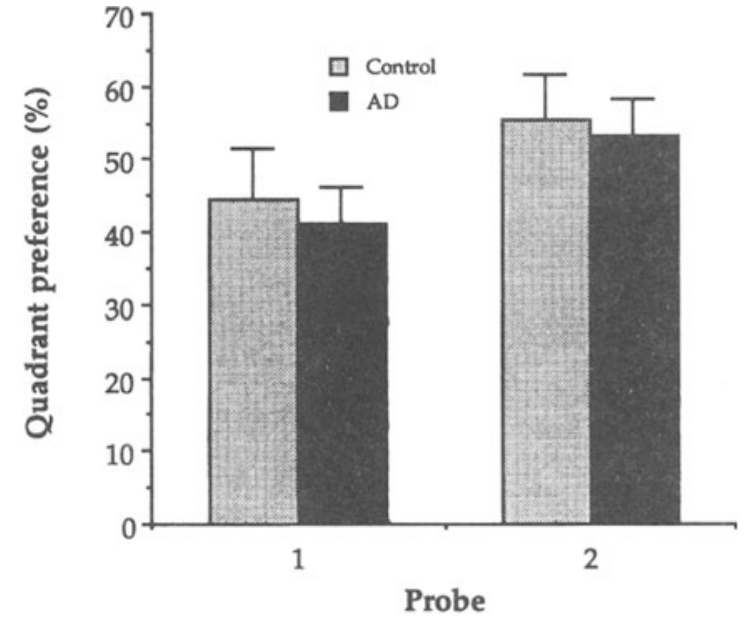

Figure 2. Average preference for swimming ( $\%$ swim distance) in the correct quadrant during the two probe trials when the hidden platform was removed from the pool.

longer than the first: $62.8 \mathrm{sec}(S E M=14.8)$ versus $19.2 \sec (S E M=6.7)$.

Both groups of rats readily learned the location of the hidden platform. This is evident from the similar improvement in mean latencies to find the platform (Figure 1) and from their preference for searching in the correct quadrant during the first and second probe trials with the platform removed (Figure 2). An analysis of variance (ANOVA) with repeated measures was conducted on the time to find the hidden platform on each trial to assess differences between groups and across trials. The difference between groups was not statistically significant $[F(1,10)=.8, p=.4]$. The decrease in time to find the platform across trials was statistically significant $[F(39,390)=11.97, p<.001]$, but the interaction between group and trial was not $[F(30,390)=1.01, p>$ .4]. Similarly, the results of an ANOVA with repeated measures on percentage of swim distance in the correct quadrant on the two probe trials revealed no difference between groups $[F(1,10)=.9, p=.5]$, a significant increase across trials $[F(1,10)=8.72, p<.02]$, and no significant interaction between group and trial $[F(1,10)=.9$, $p=.5]$.

\section{Experiment 2}

Similar to the results of Experiment 1, we found that the duration of the last induced $A D$ was longer than the first: $73.2 \mathrm{sec}(S E M=16.2)$ versus $18.6 \mathrm{sec}(S E M=6.5)$.

Before the beginning of stimulation sessions, both groups of rats learned to locate the hidden platform efficiently in its new position each day. Figure 3 presents the mean latency to find the hidden platform on Trials 1-4 averaged across the first block of 3 days (top panel) of training in the original room and last block of 3 days (bottom panel). Only the first four trials are shown for direct comparison with poststimulation performance, and in 

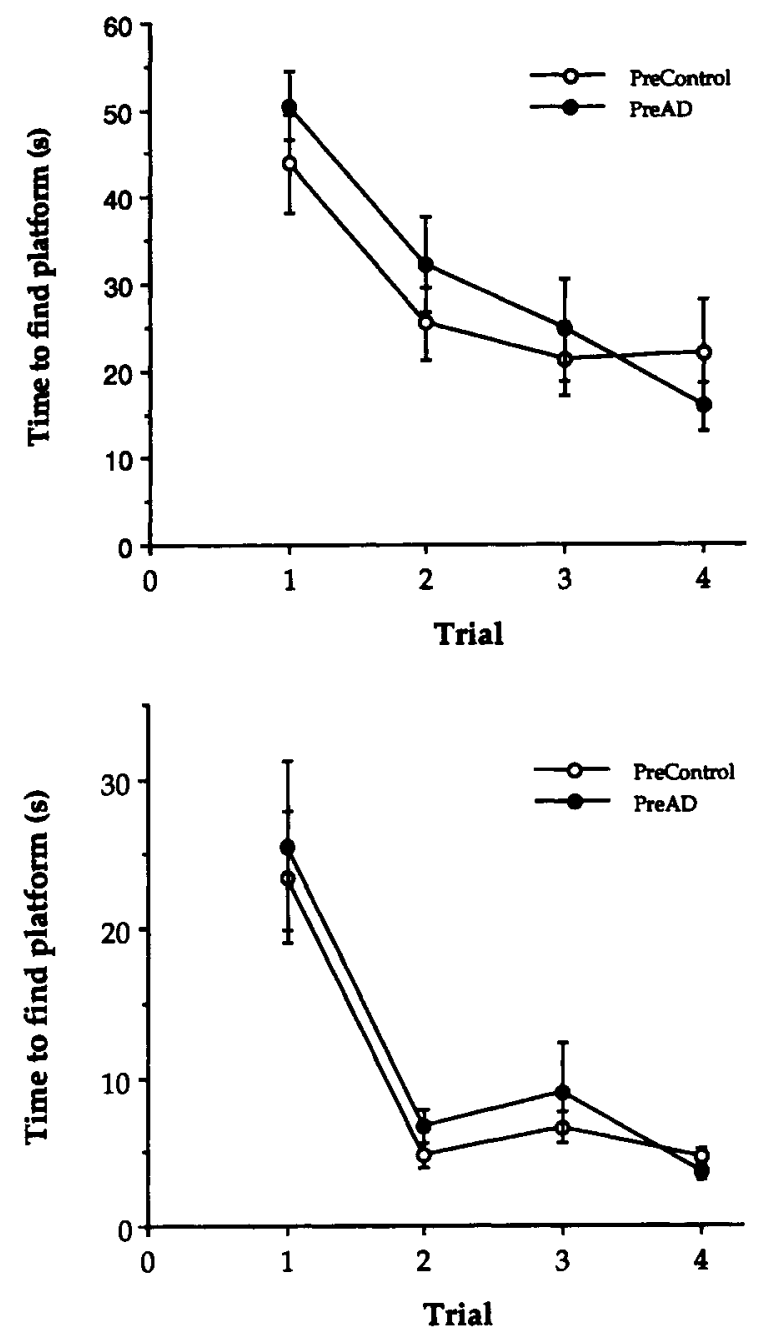

Figure 3. Average time to find the hidden platform on Trials 1-4 averaged across the first block of 3 days of training in the original room (top panel) and across the last block of 3 days of training before afterdischarges (ADs; bottom panel).

each case, training performance on Trials 5-8 was not reliably different from that on Trial 4 . An ANOVA with repeated measures revealed no significant differences between groups on latency to find the platform on the first block $[F(1,16)=.8, p>.5]$ or the last block of training $[F(1,16)=.9, p>.4]$. In contrast, the performance of rats receiving $20 \mathrm{ADs}$ was worse than that of controls 1 day $(20-24 \mathrm{~h})$ after the last AD session in both the original and new pool rooms (Figures 4 and 5). The differences between groups were statistically significant in both the original training room $[F(1,16)=9.2, p<.008]$ and in the new room $[F(1,16)=27.4, p<.001]$. Followup comparisons revealed that in both rooms the performance of the groups was not significantly different by the fourth trial.

A similar pattern was evident during test sessions in both rooms 1 week after the last AD (Figures 6 and 7). The differences between groups were significant in both the original room $[F(1,16)=10.1, p<.006]$ and in the new room $[F(1,16)=5.1, p<.04]$. Follow-up comparisons revealed that Trials 1,3 , and 4 in the old room and Trial 3 performances in the new room significantly differed between groups. In contrast, by the test sessions at 1 month (Figures 8 and 9), the differences in time to find the platform were not statistically significant in the original room $[F(1,16)=1.1, p=.3]$ or in the new room $[F(1,16)=.9$, $p=.4]$.

We calculated a correlation between the duration of the last $\mathrm{AD}$ for each rat and the difference between time to find the platform on Trial 1 and on Trial 2 in the new room on Day 1. The correlation coefficient was not statistically significant $(r=-.23)$. Finally, we calculated average swim speeds for both groups across the trials dur-

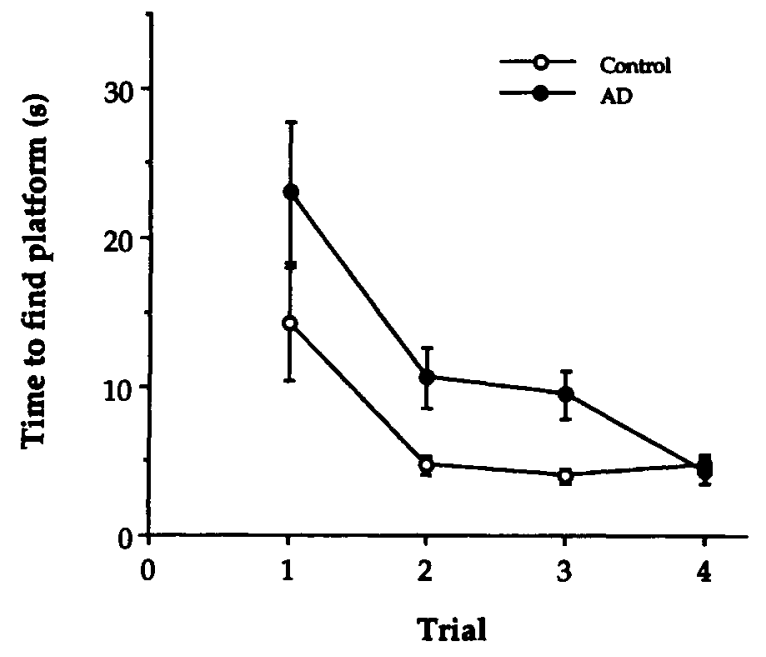

Figure 4. Average time to find the hidden platform on Trials 1-4 in the original room 1 day after the last afterdischarge (AD) session.

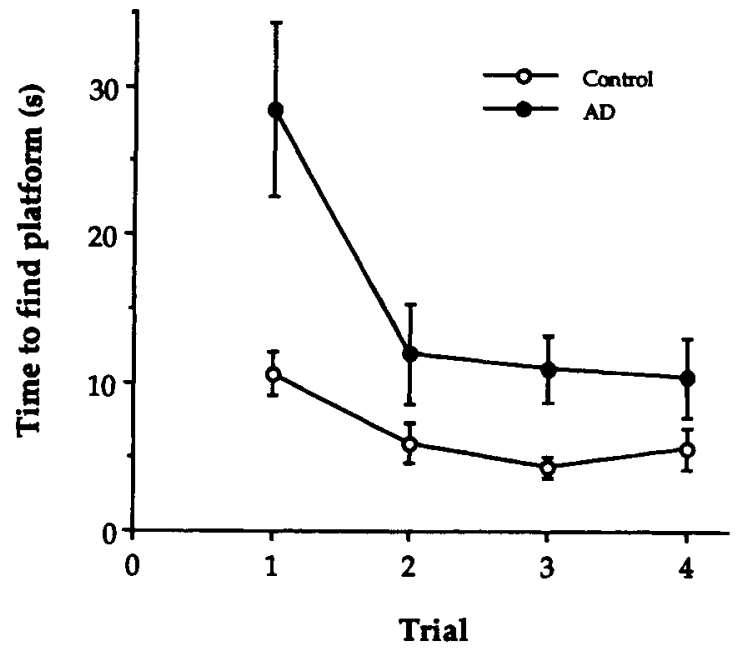

Figure 5. Average time to find the hidden platform on Trials 1-4 in the new room 1 day after the last afterdischarge (AD) session. 


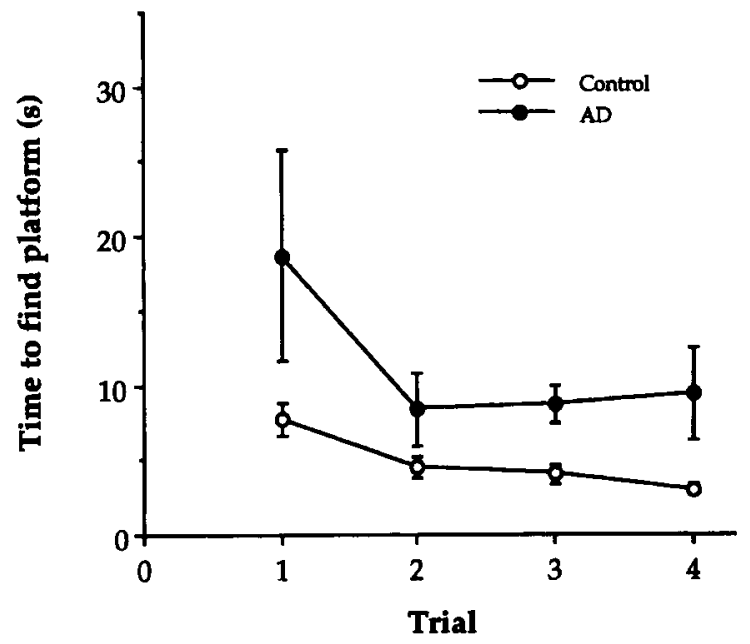

Figure 6. Average time to find the hidden platform on Trials 1-4 in the original room 1 week after the last afterdischarge (AD) session.

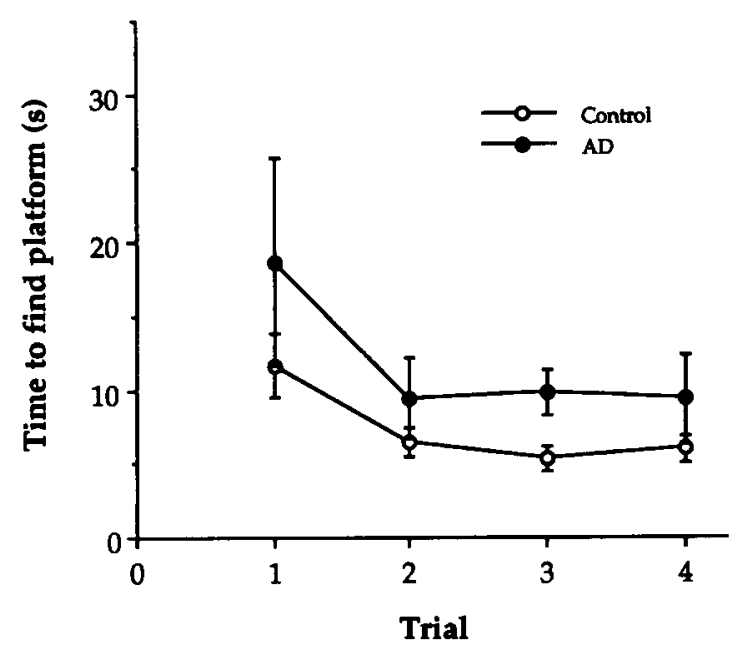

Figure 7. Average time to find the hidden platform on Trials 1-4 in the new room 1 week after the last afterdischarge (AD) session.

ing Day 1 testing. The difference was not significantly different $[F(1,16)=1.8, p=.2]$.

\section{DISCUSSION}

Repeated hippocampal ADs produced by electrical stimulation of area $\mathrm{CAl}$ in rats can affect place learning in the Morris water task for at least 1 week after the ADs stop. This finding confirms and extends prior reports by Leung (1990) using a similar partial kindling procedure and testing behavior in the radial arm maze. Thus, the changes in circuitry wrought by repeated hippocampal ADs can have relatively long-lasting functional consequences. The measurement of place learning by rats used in conjunction with the partial hippocampal kindling paradigm promises to be a fruitful avenue for exploring the relationship between physiological abnormalities associated with epileptiform processes and functional, behavioral outcomes.

It is important to note some clarifications of the interpretation of the present results. First, it is clear that the behavioral deficit after a series of hippocampal ADs does not reflect a generalized or profound impairment of learning; rather, the deficit appears to be a subtle one. The deficit does not even generalize to all forms of place learning (see Experiment 1; Leung, Brzozowski, \& Shen, 1995). To date, a disruption in performance has been observed only in the Morris water task with the hidden platform moving from day to day and in the radial arm maze - not in naive rats initially acquiring place navigation or radial arm maze behavior. Our results confirm those of Cain et al. (1993) and McNamara et al. (1993), showing no

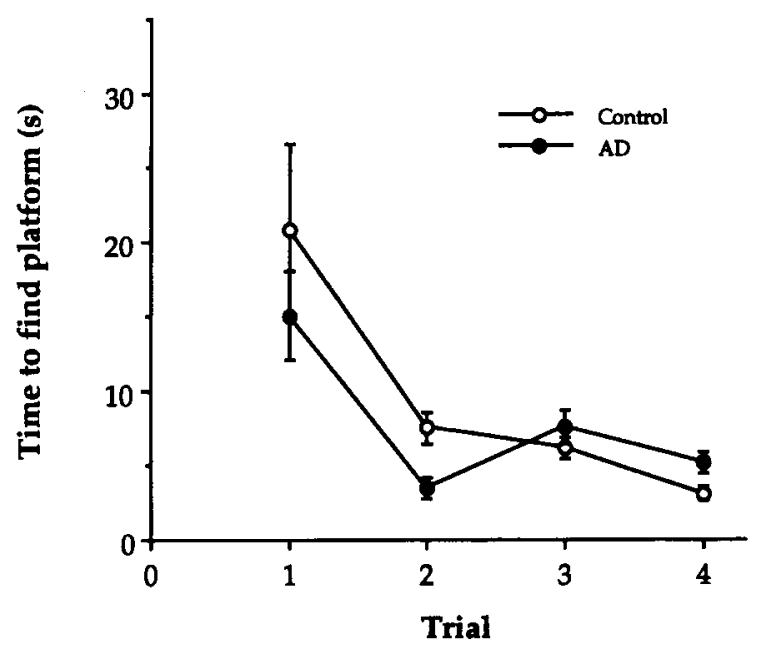

Figure 8. Average time to find the hidden platform on Trials 1-4 in the original room 1 month after the last afterdischarge (AD) session.

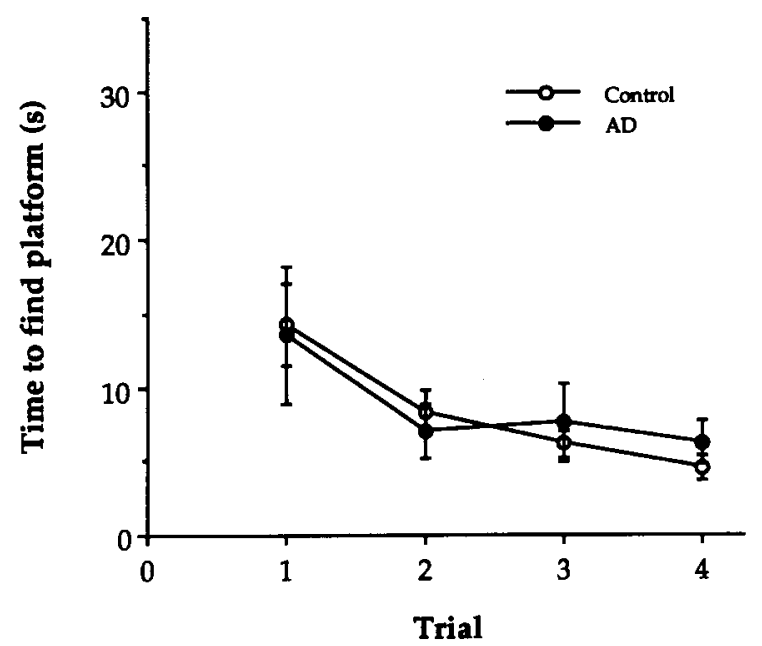

Figure 9. Average time to find the hidden platform on Trials 1-4 in the new room 1 month after the last afterdischarge (AD) session. 
deficit after partial kindling in the fixed hidden platform version of the Morris water task. A possibility that cannot be excluded for the present data is that if stimulation were delivered bilaterally, a more robust spatial learning impairment might be produced.

Second, we cannot with any degree of certainty establish that the local changes in hippocampal circuitry caused by repeated ADs are the necessary and sufficient bases for the behavioral deficits. Nonetheless, our current understanding of the consequences of partial kindling is consistent with this idea for the present results. For example, it has been shown (Leung \& Shen, 1991; Leung et al., 1994) that long-lasting functional changes are probably affecting both glutamatergic and GABAergic synapses in CAl after partial kindling, and Auer et al. (1989) have shown that subtotal CAl damage can produce a deficit in the moving hidden platform task. Of further interest, similar to the present findings with partial kindling, the partial CA1 damage described by Auer et al. (1989) does not affect acquisition of the fixed location hidden platform version of the Morris water task. However, it must be remembered that even partial kindling has widespread effects, almost certainly involving amygdala, entorhinal, subicular, and other circuitry (Leung, 1987), each of which may contribute to functional impairments. A definite conclusion concerning this point must await the results of experiments in which the modifications of CA 1 circuitry caused by partial kindling can be selectively blocked or reversed. It should be noted that we have not seen damage to CA1 in Nissl-stained sections. Furthermore, work by Cavalos, Das, and Sutula (1994) demonstrated hippocampal cell loss after generalized seizures but not after partial kindling. Thus, it is unlikely that detectable cell loss was produced by our stimulation parameters.

Third, our deficit in the Morris water task does not appear to be as long lasting as the deficit in the radial arm maze reported by Leung and Shen (1991) using similar $\mathrm{AD}$ procedures. One possibility is that the greater number of behavioral test trials after ADs in the present study facilitated recovery from the deficit. A second possibility is that the two tasks differ in the extent to which they burden processing in the affected neural circuits. One obvious difference between the two tasks involves the number of locations to which the subject must respond differentially each day. The radial arm maze has eight locations relevant for each test session, whereas in the Morris water task, there is a single location each day.

Fourth, it must be acknowledged that since we used the same sequence of hidden platform locations for all rats during post-AD testing, it may be possible that a different set of locations would have been less difficult and therefore would not have revealed a deficit.

What, then, is the nature of the behavioral deficit after partial hippocampal kindling? We suggest that the physiological changes accompanying repeated hippocampal ADs disrupt performance if the subject must respond to ambiguous cues. In the case of place learning in the radial arm maze or Morris water task, there are two sources of cue ambiguity or interference. First, locations within the experimental apparatus are defined in part by the way the cues look from different vantage points. Views from adjacent locations are composed of essentially the same cues, which differ in their specific arrangement. Whether a rat should approach, turn left, and so on, depends on discriminating different conjunctions among overlapping cue sets. A second source of ambiguity or interference derives from the fact that in both tasks the location of the goal, both food pellet and hidden platform, changes relative to the stable cues in the experimental context. In the pool, the previous day's learning should produce some interference with the place navigation that must be acquired today. In the radial arm maze, since each baited arm is visited within a session, its valence must change. Thus, on our view the deficit is not limited to retrograde amnesic symptoms, but applies to any situation that places demands on efficient processing in the hippocampal circuitry.

This way of characterizing the deficit is compatible with several positions on the nature of the hippocampal system's involvement in learning and memory, especially the views of Cohen and Eichenbaum (1993) and Gaffan (1991), and is an elaboration of the view articulated in Rudy and Sutherland (1995) and Sutherland and Rudy (1989). Our view predicts that it should be possible to enhance or reduce the behavioral impairment in any learning and memory task by increasing or decreasing cue ambiguity or interference. The results of the present Experiment 1 can be interpreted in this light. Learning to navigate to a single location with unchanging relationship to all available distal cues is the simplest form of true place learning: All experiences with the context cues generate compatible navigational tendencies. Likewise, removing a source of cue ambiguity in the radial arm maze should markedly reduce the partial kindling deficit, as when goal locations are marked by unambiguous landmarks (obviating the need to use ambiguous distal cue conjunctions). Exactly this result has been obtained in a recent experiment by Leung, Brzozowski, and Shen (in press).

In summary, we have extended the observations of Leung and co-workers that partial hippocampal kindling can produce relatively long-lasting behavioral deficits. In rats that were experienced in the Morris water task, we found that a series of 20 repeated hippocampal ADs caused a deficit in the moving-platform version of the Morris water task that lasted at least 1 week. In contrast, in rats that were naive to the task, we found that acquisition of the single fixed platform location was not sensitive to partial kindling. These results show that the partial hippocampal kindling paradigm may afford a useful window into functionally significant physiological changes that take place in the development of epileptic disorders.

\section{REFERENCES}

Auer, R. N., Jensen, M. L., \& Whishaw, I. Q. (1989). Neurobehavioral deficit due to ischemic brain damage limited to half of the $\mathrm{CAl}$ sector of the hippocampus. Journal of Neuroscience, 9, 1641-1647. 
Cain, D. P., Hargreaves, E. L., Boon, F., \& Dennison, Z. (1993). An examination of the relations between hippocampal long-term potentiation, kindling, afterdischarge, and place learning in the water maze. Hippocampus, 3, 153-164.

Castro, C. A., Silbert, L. H., McNaughton, B. L., \& Barnes, C. A. (1989). Recovery of spatial learning deficits after decay of electrically induced synaptic enhancement in the hippocampus. Nature, 342, 545-548.

Cavalos, J. E., Das, I., \& Sutula, T. P. (1994). Neuronal loss induced in limbic pathways by kindling: Evidence for induction of hippocampal sclerosis by repeated, brief seizures. Journal of Neuroscience, 14, 3106-3121.

Cohen, N. J., \& Eichendaum, H. (1993). Memory, amnesia, and the hippocampal system. Cambridge, MA: MIT Press.

GAFFAN, D. (1991). Spatial organization of episodic memory. Hippocampus, 1, 262-264.

HALGREN, E., \& Wilson, C. L. (1985). Recall deficits produced by afterdischarges in the human hippocampal formation and amygdala. Electroencephalography \& Clinical Neurophysiology, 61, 375-380.

KESNER, R. P., \& DOTY, R. W. (1968). Amnesia produced in cats by local seizure activity initiated from the amygdala. Experimental Neurology, 21, 58-68.

Knowlton, B. J., Shapiro, M. L., \& Olton, D. S. (1989). Hippocampal seizures disrupt working memory performance but not reference memory acquisition. Behavioral Neuroscience, 103, 1144-1147.

LEUNG, L. S. (1987). Hippocampal electrical activity following local tetanization: I. Afterdischarges. Brain Research, 419, 173-187.

LEUNG, L. S. (1990). Spontaneous hippocampal interictal spikes following local kindling: Time-course of change and relation to behavioral seizures. Brain Research, 513, 308-314.

Leung, L. S., BoON, K. A., Kaibara, T., \& InNIS, N. K. (1990). Radial maze performance following hippocampal kindling. Behavioural Brain Research, 40, 119-129.

LeUng, L. S., Brzozowski, D., \& Shen, B. (1995). Radial arm maze performance after partial hippocampal kindling. Neuroscience $A b-$ stracts, 21, 1972.

Leung, L. S., Brzozowski, D., \& Shen, B. (in press). Radial arm maze performance after partial hippocampal kindling. Behavioral Neuroscience.

LEUNG, L. S., \& SHEN, B. (1991). Hippocampal CAl evoked response and radial 8-arm maze performance after hippocampal kindling. Brain Research, 555, 353-357.

Leung, L. S., Zhao, D., \& Shen, B. (1994). Long-lasting effects of partial hippocampal physiology and function. Hippocampus, 4 , 696-704.

Lopes da Silva, F. H., Gorter, J. A., \& Wadman, W. J. (1986). Kindling of the hippocampus induces spatial memory deficits in the rat. Neuroscience Letters, 63, 115-120.

MCDonough, J. H., JR., \& KesNer, R. P. (1971). Amnesia produced by brief electrical stimulations of the amygdala or dorsal hippocampus in cats. Journal of Comparative \& Physiological Psychology, 77, 171-178.

McNamara, R. K., Kirkby, R. D., DePape, G. E., \& Corcoran, M. E. (1993). Limbic seizures, but not kindling, reversibly impair place learning in the Morris water maze. Behavioural Brain Research, $\mathbf{5 0}$, 167-175.
Morris, R. G. M. (1981). Spatial localization does not require the presence of local cues. Learning \& Motivation, 12, 239-261.

MoRRIS, R. G. M. (1983). An attempt to dissociate "spatial-mapping" and "working-memory" theories of hippocampal function. In W. Seifert (Ed.), Neurobiology of the hippocampus (pp. 405-432). London: Academic Press.

Morris, R. G. M., ANDERSon, E., LyNCh, G. S., \& Baudry, M. (1986). Selective impairment of learning and blockade of long-term potentiation by an $\mathrm{N}$-methyl-D-aspartate receptor antagonist, AP5. $\mathrm{Na}$ ture, 319, 774-776.

Morris, R. G. M., Garrud, P., Rawlins, J. N. P., \& O'KeEFE, J. (1982). Place navigation impaired in rats with hippocampal lesions. Nature, 297, 681-683.

O'KEEFE, J., \& NADEL, L. (1978). The hippocampus as a cognitive map. London: Oxford University Press, Clarendon Press.

Olton, D. S., Becker, J. T., \& HandelmanN, G. E. (1979). Hippocampus, space, and memory. Behavioral \& Brain Sciences, 2, 313 365.

Olton, D. S., \& Wolf, W. A. (1981). Hippocampal seizures produce retrograde amnesia without a temporal gradient when they reset working memory. Behavioral \& Neural Biology, 33, 437-452.

RUDY, J. W., \& SUTHERLAND, R. J. (1995). Configural association theory and the hippocampal formation: An appraisal and reconfiguration. Hippocampus, 5, 375-389.

Sutherland, R. J., Dringenberg, H. C., \& Hoesing, J. M. (1993). Induction of long-term potentiation at perforant path dentate synapses does not affect place learning or memory. Hippocampus, 3, 141-147.

Sutherland, R. J., Hoesing, J. M., \& Whishaw, I. Q. (1990). Domoic acid, an environmental toxin, produces hippocampal damage and severe memory impairment. Neuroscience Letters, 120, 221-223.

Sutherland, R. J., KolB, B., \& Whishaw, I. Q. (1982). Spatial mapping: Definitive disruption by hippocampal and frontal cortex damage in the rat. Neuroscience Letters, 31, 271-276.

Sutherland, R. J., \& Rodriguez, A. J. (1989). On the role of the fornix and related subcortical structures in spatial learning and memory. Behavioural Brain Research, 32, 265-277.

SuTHERLand, R. J., \& RuDY, J. W. (1989). Configural association theory: The role of the hippocampal formation in learning, memory, and amnesia. Psychobiology, 17, 129-144.

Sutherland, R. J., WhishaW, I. Q., \& KolB, B. (1983). A behavioural analysis of spatial localization following electrolytic, kainate-, or colchicine-induced damage to the hippocampal formation in the rat. Behavioural Brain Research, 7, 133-153.

WHISHAW, I. Q. (1985). Formation of place learning-set by the rat: A new paradigm for neurobehavioral studies. Physiology \& Behavior, $35,139-143$.

WHISHAW, I. Q. (1987). Hippocampal, granule cell and CA3-4 lesions impair formation of a place learning-set in the rat and induce reflex epilepsy. Behavioural Brain Research, 24, 59-72.

(Manuscript received June 27, 1995; revision accepted for publication August 20, 1996.) 